\title{
O uso do software Google Sketchup e de material concreto para a aplicação de conceitos adquiridos nas aulas de matemática
}

\author{
Larissa Weyh Monzon - tuquinha.monzon@gmail.com \\ Instituto de Matemática - Programa de Pós-Graduação em Ensino de Matemática - \\ Universidade Federal do Rio Grande do Sul (UFRGS) \\ Porto Alegre - RS - Brasil
}

\section{Resumo}

O objetivo deste artigo é apresentar uma proposta de aplicação dos conceitos adquiridos nas aulas de matemática, adotando um projeto pedagógico que consiste na reprodução de um prédio da cidade em uma maquete, vinculando essa construção no software Google SketchUp. A proposta integra recursos manipulativos digitais e não digitais e suas implicações no processo da construção do conhecimento matemático.

Palavras-chave: tecnologia, maquete, matemática, ensino.

\section{The use of the Google SketchUp software and concrete materials for an application of the concepts acquired in the mathematics classes}

\begin{abstract}
This article's goal is to present an proposal of application of the concepts acquired in the mathematics classes, adopting a pedagogic project that consists in the reproduction of a building from the city in a model, linking this building in the Google SketchUp software. The proposal integrates digital and non digital manipulative resources and its implication in the building process of the mathematics knowledge.
\end{abstract}

Palavras-chave: tecnology, model, mathematics, teaching.

\section{Introdução}

A proposta deste trabalho é contextualizar saberes matemáticos. Os conceitos adquiridos nas aulas de matemática são mobilizados para a construção de uma maquete de um prédio, utilizando para isso recursos manipulativos digitais e não digitais. Em suma, os saberes matemáticos em uma situação real.

Maltempi (2005), declara que o aprendizado somente ocorre quando o aluno está envolvido na construção de um objeto que apresenta algum significado para ele, algo que poderá mostrar, comentar e discutir com outras pessoas. Assim, os conceitos da matemática poderão ser alcançados de uma forma mais sólida pelo aprendiz quando ele os usa em algo que construiu.

A inter-relação dos conhecimentos matemáticos apresentados em sala de aula ao dia a dia do aprendiz é cada vez mais indispensável, de acordo com Azevedo (2008), os alunos questionam sobre a aplicação e buscam saber onde poderiam utilizar tais conhecimentos.

Refletindo sobre esses pontos, provém a proposta de aplicar os conceitos das relações trigonométricas e proporcionalidade construindo uma maquete. Segundo os PCN's - Parâmetros Curriculares Nacionais (1998) o uso de maquetes na aula de 
matemática contribui para aprimorar a imagem visual dos alunos. Obtendo a representação das diferentes vistas de um objeto, desenvolvendo a intuição de localização, movimentação no espaço, proporcionalidade e escalas.

[...] a proporcionalidade e a escala estão presentes em muitas situações reais. Observa-se uma variedade de situações em que se faz necessário a mobilização de certos processos cognitivos que envolvem e colocam em prática os conceitos e noções relacionadas à proporcionalidade. Tinoco (1996), coloca que o conceito de proporcionalidade é essencial ao aprendizado de muitos conteúdos de diversas disciplinas ensinadas na educação básica e no terceiro grau (Geografia, Física, Química, Farmácia, etc.). (Noro et al., 2008, p.4)

Convicto que os alunos podem ser os atores principais do seu aprendizado, com uma postura ativa nas tomadas de decisões e nas concretizações das tarefas, desenvolvendo também sua atitude como futuro profissional competente, e tendo o recurso das tecnologias na sala de aula como uma poderosa ferramenta para essa finalidade, é apresentada tal proposta. Dirigida a alunos da $8^{\text {a }}$ série do ensino fundamental, pois é o momento que eles são familiarizados com as relações trigonométricas no triângulo retângulo e já adquiriram nessa série ou em séries anteriores os conceitos de proporcionalidade, de geometria e de escala necessários para esse projeto.

A seção dois desse artigo faz o confronto da utilização e da contribuição do uso de instrumentos digitais e não digitais no ensino de matemática. Na terceira seção é apresentado o recurso digital que será empregado nessa proposta, dando suas referências, propriedades e já que se trata de um software que não foi construído diretamente para o uso no ensino de matemática, e sim uma ferramenta de trabalho de arquitetos e engenheiros, é demonstrada sua validação do possível emprego nas escolas. Na quarta parte é relatada a experiência desenvolvida e como está sendo a recepção dos alunos que irão diligenciar tal tarefa. E, finalmente na última parte são apontadas as expectativas quanto ao seu emprego e possíveis conclusões da sua aplicação.

\section{$2 \quad O$ uso de recursos manipulativos digitais e não digitais}

A utilização de materiais concretos nas aulas de matemática já foi e é tema de várias discussões entre os pesquisadores na área da educação matemática, como é mencionado em Hoffmann et al (2009). No momento, temos outro fator que se agrega a essas discussões de uma forma imediata: o uso das tecnologias digitais, que, como o material concreto, podendo ser manipulativos, facilitam a visualização e conceituam diversos aspectos matemáticos.

Quando um aluno pode mexer, interagir, se envolver, construir um objeto que é veículo de um conceito do seu aprendizado, este saber se procede de uma forma mais direta.

A construção de conhecimento envolve implicações entre significações, assim, das ações aos enunciados, as significações resultam de suas aplicações, ou seja, das relações e das coordenações estabelecidas pelo sujeito. Enfim, para construir conhecimento, é preciso reestruturar as significações anteriores - a ideia que o aprendiz traz consigo -, produzindo diferenciações e integrando as novas significações ao sistema de significados do sujeito. Essa integração resulta da atividade de diferentes sistemas lógicos do sujeito, que interagem entre si e com os objetos a assimilar ou com os problemas a resolver. A aprendizagem fica vinculada à interação do aprendente com seu objeto de estudo.(Hoffmann et al., 2009, p. 2) 
Conforme Noro et al. (2008), os ambientes interativos, como também os computadores, desenvolvem um papel essencial para a comunicação e interação entre os sujeitos aprendizes. É através dessas interações que os alunos desencadeiam trocas, estratégias de construção, compartilhamento de idéias para resolverem situações problemas.

O uso da informática na educação, concordando com Maltempi (2005), é ter o computador como auxílio no processo de aprendizagem, numa abordagem de construção de conhecimento. Ressaltando que o uso da tecnologia na sala de aula não é sinônimo de solução no ensino, mas sim de um instrumento, mas a sua falta implica em uma má educação, pois a escola deve preparar o aluno para a vida, para o mercado de trabalho. Em suma, a escola não deve se deslocar dessa tecnologia que está inserida em todos os meios neste momento e que pode trazer muitos benefícios para o aprendizado dos nossos alunos.

Os recursos nas aulas de matemática, sendo digitais ou não digitais, auxiliam no processo de aprendizagem, fazem com que os alunos explorem e contextualizem seus conceitos e propriedades, e ainda, quanto mais diversificadas forem as formas, segundo Hoffmann et al. (2009), com os quais os alunos podem explorar, interagir e manipular, mais intenso serão as trocas entre os pares e com o professor e maiores as probabilidades de que os saberes matemáticos sejam compreendidos e assimilados.

\section{$3 \quad$ O software SketchUp nas aulas de matemática}

O Google SketchUp é uma ferramenta intuitiva e de fácil manipulação desenvolvida pelo Google que possibilita a criação de ambientes em 3D.

Um dos principais grupos de usuários do software são arquitetos e engenheiros.

Segundo Furtado (2010), qualquer que seja a tecnologia disponível é preciso avaliá-la, perante sua pertinência, sua utilidade, seu custo e seu benefício. Com esta análise, concluindo-se a sua eficácia, eficiência, efetividade, cabe assim utilizá-la.

Esse software proporciona situações onde podem ser explorados muitos conceitos de matemática, tanto de geometria plana e espacial, como nos procedimentos da construção civil que utilizam as concepções matemáticas, podendo trazer para a sala de aula uma experiência matemática divertida para os alunos.

Ele pode ser utilizado como uma representação gráfica digital muito interessante e curiosa para os alunos, capacitando-os no desenvolvimento de raciocínio lógico e explorando os conhecimentos matemáticos na sua manipulação. Ainda, desperta a construção de situações muito reais aos alunos.

Os programas que criam ambientes, onde a Geometria se apresenta com clareza, constituem ferramentas importantes para superar obstáculos de aprendizagem. Nesses ambientes, os conceitos geométricos são construídos com equilíbrio conceitual e figural, as habilidades em perceber diferentes representações de uma mesma situação se desenvolvem e a descoberta de propriedades e conceitos ficam mais fáceis.(Flores, Santos, 2004, p. 10)

Como qualquer outro recurso, este também precisa da intervenção do professor, para realmente explorar suas utilidades e eficácias perante o ensino de matemática. A simples presença dessa tecnologia não garante qualidade de ensino e nem da concretização dos conceitos a serem explorados. 


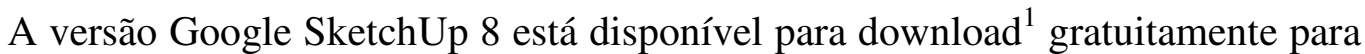
qualquer pessoa que deseja utilizá-lo e ainda, existem diversos tutoriais em vídeos e uma central de ajuda muito eficiente, deixando seus recursos claros e explicados para que qualquer pessoa possa entender e criar modelos em 3D.

Sua manipulação requer conhecimentos de retas, pontos, planos, ângulos, figuras planas, paralelismo, perpendicularismo, dimensões, enfim, uma gama de conceitos matemáticos que são explorados nesse componente. Assim, fica evidente que é uma ótima ferramenta a ser utilizada nas aulas de matemática, fazendo a exploração de diversos campos da geometria.

A Figura 1 apresenta a tela inicial do software com suas principais ferramentas, na imagem fica óbvia a exploração do Sistema Cartesiano Ortogonal.

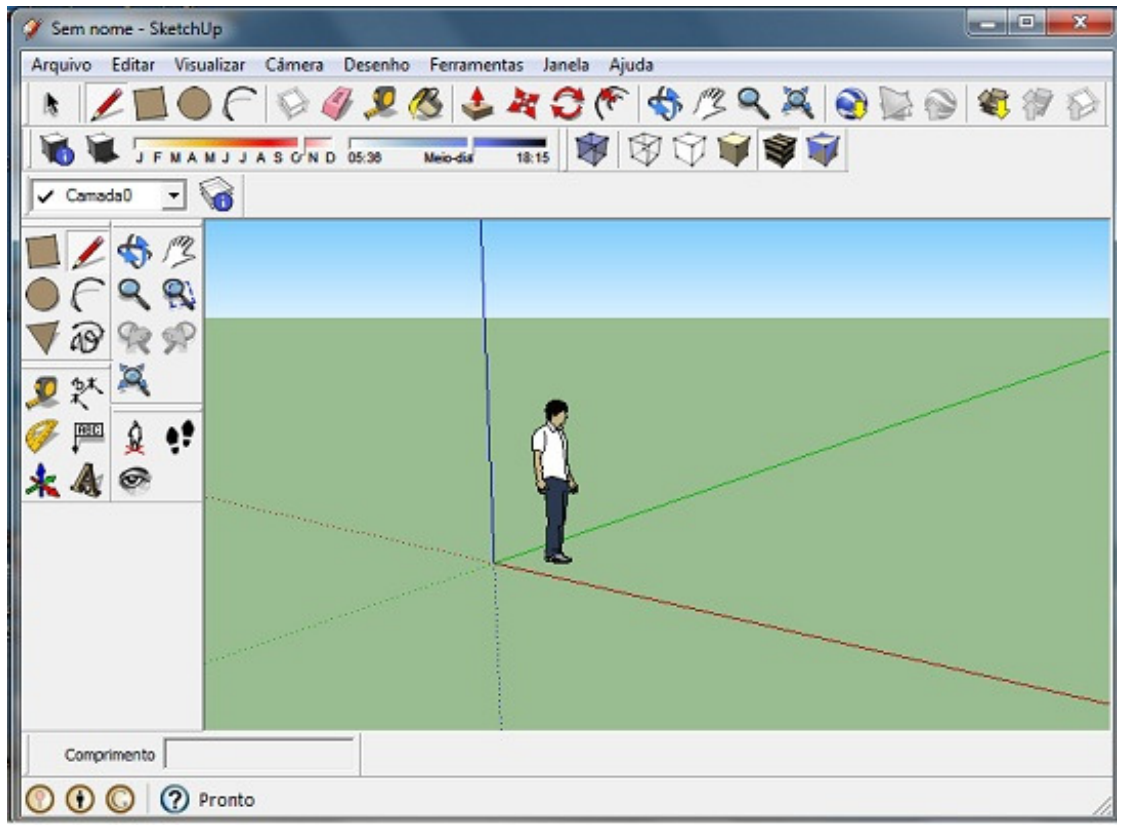

Figura 1 - Tela inicial do SketchUp

\section{$4 \quad$ Uma proposta de trabalho}

A significação de um objeto resulta da atividade que o sujeito tem com ele, as suas atribuições, relações e propriedades geram significados e conceitos aos alunos quando eles interagem e manipulam com esse objeto.

A construção do conhecimento matemático exige significação dos seus conceitos, que para isso, o estudante necessita construí-lo através da interação, manipulação e aplicação em algo real.

Diante desses princípios proponho a seguinte arquitetura pedagógica que agrega essas convicções, onde o aluno explora os conceitos matemáticos criando e aplicando em uma situação muito próxima de sua realidade.

A seguinte experiência está em fase de desenvolvimento em duas turmas de $8^{a}$ série do Ensino Fundamental de uma Escola Estadual de Campo Bom. A escola, recentemente, ganhou do governo estadual e federal, um laboratório novo de informática, pois até o momento não disponibilizava tal recurso para os professores utilizarem nas suas aulas. A recepção foi bem grande, mais da parte dos alunos do que

\footnotetext{
${ }^{1}$ Disponível em http://sketchup.google.com/download/
} 
dos professores, estes, por sua vez, ainda apresentam receio em levar os estudantes para o laboratório de informática, devido a sua pouca experiência em recursos digitais.

Percebo que os poucos professores que já fazem uso desse recurso exploram mais a parte de pesquisa na Internet, que se trata de uma rica ferramenta para essa finalidade, mas não usam a informática para as outras finalidades que são inúmeras, tanto para o desenvolvimento do raciocínio, do pensamento e da criatividade do alunado.

Este fato concorda com Krahe, Torouco e Konrath (2006), que ressaltam que é um grande desafio para os professores ingressarem dentro desse novo contexto da educação tecnológica, onde devem encontrar tempo para conhecer todas essas novas tecnologias, atualizar-se e planejar o seu uso, avaliando sua aplicabilidade e sua eficiência perante sua classe de estudantes.

A proposta de atividade que este artigo traz tem a finalidade de que os alunos possam fazer uso dos conhecimentos que adquiriram nas aulas de matemática na construção da réplica de um prédio da sua cidade onde residem.

Depois que exploraram os conceitos das relações trigonométricas nos triângulos retângulos e seu uso para medir alturas inacessíveis, os alunos, reunidos em grupos de no máximo cinco componentes, construíram e aprenderam a usar um teodolito caseiro como mostra na Figura 2.

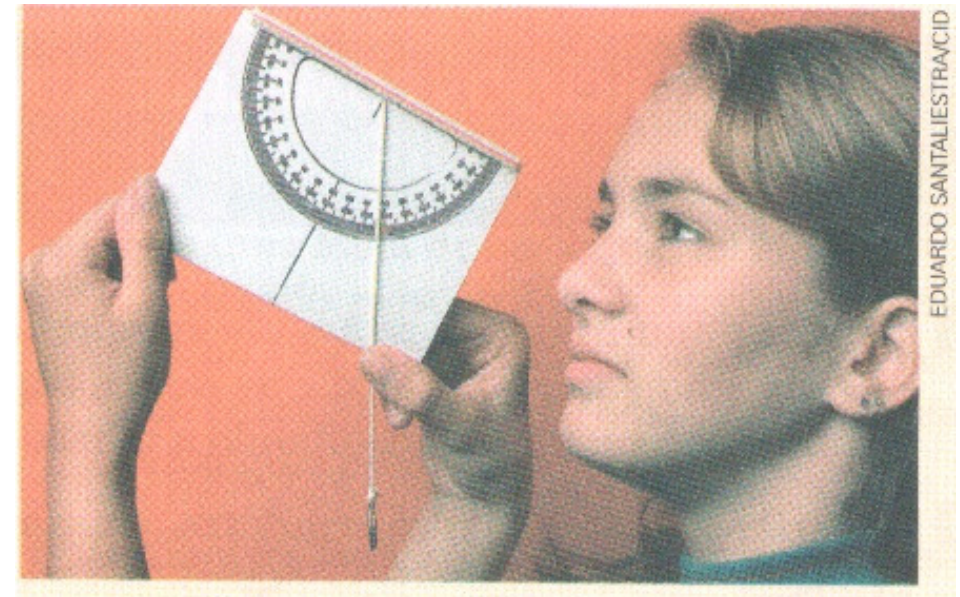

Figura 2 - Teodolito caseiro

Material necessário para a confecção do teodolito: um pedaço de papelão $(10 \mathrm{~cm}$ x $15 \mathrm{~cm}$ ) com a imagem de um transferidor de $180^{\circ}$, um pedaço de barbante de $20 \mathrm{~cm}$, um canudo plástico, um peso pequeno (uma moeda ou argola de metal) ${ }^{2}$.

Para incentivar a construção e a escolha de um prédio conhecido de sua cidade, os alunos assistiram um vídeo ${ }^{3}$ que ensina as ferramentas básicas do Google SketchUp, essas ferramentas que já são suficientes para conseguir realizar a proposta do trabalho. Diante desse vídeo, os alunos ficaram bastante interessados em usar esse software, poder explorá-lo e verificar seus recursos, o que trouxe o êxito de um dos objetivos da proposta que é despertar o interesse da turma.

No atual momento, os alunos estão explorando as construções de sua cidade, fazendo a escolha de alguma delas. Usando seu teodolito irão medir a altura desse

\footnotetext{
${ }^{2}$ Imagem e material necessário retirado do livro didático Matemática de Edwaldo Bianchini, editora Moderna, São Paulo 2006.

${ }^{3}$ Disponível em http://www.youtube.com/watch?v=V6RwO6A4aV4 e http://www.youtube.com/watch?v=5T_71DWzFQ
} 
prédio como aprenderam nas aulas de matemática, usando as relações trigonométricas. Para poder fazer a réplica, o prédio deverá ser fotografado de vários ângulos, podendo assim ser selecionado a melhor foto, ou seja, a que apresenta uma melhor definição do prédio escolhido.

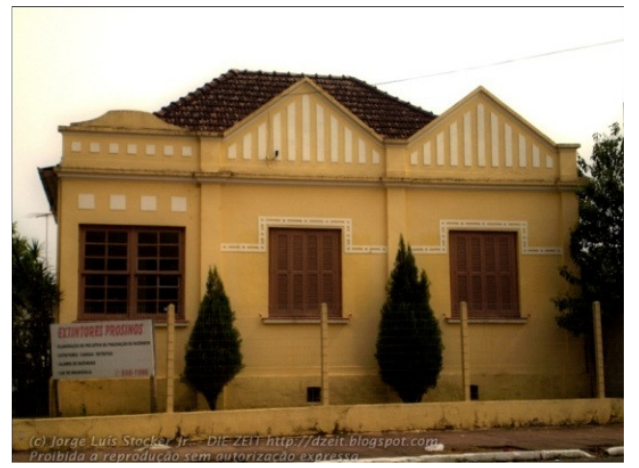

Figura 3 - Exemplo de um prédio histórico de Campo Bom

Com a medida da altura e selecionada a melhor foto, irão aplicar os conceitos de proporcionalidade de segmentos para calcular as outras medidas do prédio. Por exemplo, se mediram a altura do prédio como 10 metros e na foto essa altura está representada por $5 \mathrm{~cm}$ e a largura por $2 \mathrm{~cm}$, os alunos poderão constatar que a largura real do prédio é de aproximadamente 4 metros (usando o conceito de proporcionalidade). $\mathrm{O}$ uso da foto nesse caso, pode trazer imprecisões nas medidas, mas desconsideraremos, pois não influenciam no objetivo que o trabalho quer atingir.

Diante de todas as medidas os alunos representarão no Google SketchUp o prédio que escolheram, neste momento os alunos explorarão várias definições de retas, ângulos, figuras, planos da geometria e poderão visualizar sua construção em todas suas dimensões. O software ainda traz diversos recursos de arquitetura, logo os alunos poderão escolher pisos, texturas, cores, enfim, fazer uma réplica virtual muito próxima da construção real.

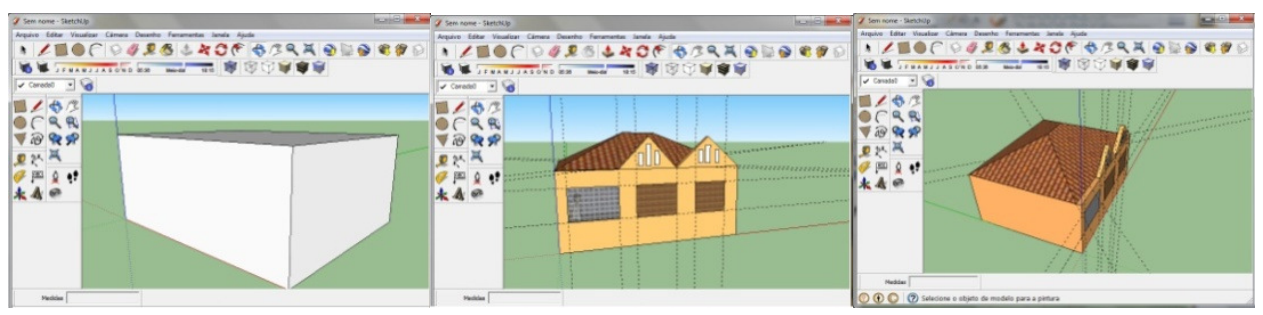

Figura 4 - Construção do prédio no Google SketchUp

Neste momento, fica a critério do professor, a opção de trabalhar com a matemática financeira. Os alunos podem verificar, através de pesquisa de preços, das dimensões calculadas do prédio, do material utilizado o que poderia ser custo para construí-lo.

E finalmente, explorando e vinculando os recursos manipulativos digitais e não digitais, com o auxílio da professora de artes, e entra nesse momento a interdisciplinaridade, o uso da matemática nas diferentes áreas de ensino, na construção da maquete. Nesse momento, o aluno se confrontará com o conceito de escala, já que o Google SketchUp proporciona as medidas reais da construção. Na construção da maquete, os alunos deverão reduzir suas medidas, verificando uma escala mais adequada, os materiais necessários e convenientes para essa obra.

Diante da imagem virtual e da maquete, os alunos poderão refletir e discutir sobre as duas ferramentas disponíveis, os benefícios e malefícios de cada uma. Através 
de uma discussão em grande grupo, o professor pode explorar dos seus alunos seus argumentos de qual seria uma réplica mais eficaz e eficiente em variados setores do mercado de trabalho, onde essas ferramentas são utilizadas.

\section{$5 \quad$ Conclusões e perspectivas}

A possibilidade dos alunos usarem os conhecimentos que adquiriram nas aulas de matemática num projeto que eles criaram, que lhes despertou interesse fez com que gostassem e sentissem prazer nas aulas de matemática.

A proposta ainda alcançou a troca de experiências, de opiniões entre os grupos, debates da melhor e mais adequada escolha.

Ainda, o programa SketchUp, mostrou ser um forte aliado ao ensino de matemática, onde os alunos devem buscar conceitos de matemática já trabalhados e usar um pensamento lógico para manipular suas ferramentas. E a construção da maquete faz com que eles possam tocar, mostrar e expor para os demais sua criação como Maltempi (2005) menciona que com isso, podendo falar sobre sua criação, os alunos aprendem mais, pois eles devem entender o que fizeram para poder passar adiante.

A interação com as outras disciplinas do currículo também se faz muito eficaz, pois deixa evidente a aplicabilidade da matemática nos diferentes ramos das ciências. Um aluno para poder saber o que vai seguir, conhecer do que gosta, precisa compreender as diferentes áreas do conhecimento e desenvolvê-las, pois só assim poderá realmente perceber a sua afinidade por alguma delas e poder seguir na sua formação específica.

Com a finalização desse projeto, a aluno poderá perceber diferentes áreas de interesse e ainda fortalecer seus conhecimentos matemáticos, pois aplicará de uma forma interativa e divertida.

Esse artigo ainda pretende trazer uma nova ferramenta de trabalho muito eficaz e interessante para os professores de matemática, o software Google SketchUp, trazendo aqui, somente uma das inúmeras propostas de exploração que ele pode trazer para a educação.

\section{Referências bibliográficas}

AZEVEDO, J. L.A de. Trabalhando conceitos matemáticos com tecnologias informáticas por meio da elaboração de projetos de construção civil. São Paulo: UNESP, 2008. p. 171. Dissertação de mestrado.

BRASIL. Ministério da Educação. Secretaria da Educação Básica. Parâmetros Curriculares Nacionais de $5^{\mathbf{a}}$ a $\mathbf{8}^{\mathbf{a}}$. séries - Matemática. Brasília, 1998. Disponível em: <http://portal.mec.gov.br/seb/arquivos/pdf/matematica.pdf>. Acesso em: 12 out. 2010 .

FLORES, C.; SANTOS, C.C.G. dos. Relato de experiência: a ferramenta computacional AutoCAD como meio de aproximar a geometria da realidade na $2^{\mathrm{a}}$ série do ensino médio. In: Congresso Nacional de Educação, 2., 2004, Paraná. Paraná: Pontifícia Universidade Católica do Paraná, 2004. Disponível em < http://www.pucpr.br/eventos/educere/educere2004/anaisEvento/paginas/educere.htm> Acesso em: 10 out. 2010. 
FURTADO, A.B. Modelagem matemática com tecnologias de informação e comunicação. In: Encontro Paraense de Modelagem Matemática, 3, Marabá/PA, 2010. Disponível em:

<http://www.ufpa.br/epamm2010/media/system/Trabalhos/MC04457650200-1.pdf> Acesso em: 09 out. 2010.

HOFFMANN, D. S.; MARTINS, E. F.; BASSO, M. V. Experiências física e lógicomatemática em Espaço e Forma: uma arquitetura pedagógica de uso integrado de recursos manipulativos digitais e não digitais. In: Anais do Simpósio Brasileiro de Informática na Educação, 2009. Disponível em: <http://www.brie.org/pub/index.php/sbie/article/view/1142/1045> Acesso em: 09 out. 2010.

KRAHE, E.D.; TAROUCO, L.M.R; KONRATH, M.L.P. Desafios para o trabalho docente: mudança ou repetição. Renote, Porto Alegre, dez. 2006. Disponível em: < http://seer.ufrgs.br/renote/article/viewFile/14291/8207> Acesso em: 12 out. 2010.

MALTEMPI, M.V. Tecnologias e Conhecimento: Pesquisas em Educação matemática. In: Congresso Ibero-americano de Educação matemática, 5, 2005, Portugual, Anais. Disponível em < http://www.rc.unesp.br/igce/demac/maltempi/Publicacao/Maltempicibem.pdf> Acesso em: 10 out. 2010.

NORO, A.P.; GAZZONI, A.; LENCINA, C.C.; MATHIAS, C.V.; FIOREZE, L.A.; PINCOLINI, L.B.; ASSUMPÇÃO, P.G.S de; GUTERRES, S. Objeto de aprendizagem: A matemática das plantas de casas e mapas. Renote, Porto Alegre, jul. 2008. Disponível em: < http://seer.ufrgs.br/renote/article/viewFile/14583/8491> Acesso em: 05 out. 2010. 